\title{
Notionalization: The Transformation of Descriptions into Categorizations
}

\author{
Arnulf Deppermann
}

Published online: 13 July 2011

(C) Springer Science+Business Media B.V. 2011

\begin{abstract}
This paper analyses one specific conversational practice of formulation called 'notionalization'. It consists in the transformation of a description by a prior speaker into a categorization by the next speaker. Sequences of this kind are a "natural laboratory" for studying the differences between descriptions and categorizations regarding their semantic, interactional, and rhetorical properties:
\end{abstract}

Descriptive/narrative versions are often vague and tentative, multi unit turns, which are temporalized and episodic, offering a lot of contingent, situational, and indexical detail.

Notionalizations turn them into condensed, abstract, timeless, and often agentless categorizations expressed by a noun (phrase) within one turn constructional unit (TCU).

Drawing on audio- and video-taped German data from various types of interaction, the paper focuses on one particular practice of notionalization, the formulation of purportedly common ground by TCUs prefaced with the connective also. The paper discusses their turn-constructional and morphological properties, pointing out affinities of notionalization with language for special purposes. Notionalizations are used for reducing detail and for topical closure. They provide grounds for emergent keywords, which can be reused to re-contextualize topical issues and interactional histories efficiently. Notionalizations are powerful means for accomplishing intersubjectivity while pursuing (sometimes one-sided) practical relevancies at the same time. Their inevitably perspective design thus may lead to re-open the issue they were deemed to settle. The paper closes with an outlook to other practices of notionalization, pointing to dimensions of interactionally relevant variation and commonalities.

A. Deppermann ( $ه)$

Institut für Deutsche Sprache (IDS), R 5, 6-13, 68161 Mannheim, Germany

e-mail: deppermann@ids-mannheim.de 
Keywords Conversation analysis · Formulation · Interactional semantics · Notionalization · Categorization

Since the seminal papers by Garfinkel and Sacks (1970) and Heritage and Watson (1979), the study of formulations has become a prosperous field of study within conversation analysis. Prior research has gained insight into the ways how institutional agents use formulations for institutional concerns, e.g., in psychotherapy (Antaki et al. 2005; Antaki 2008), child counselling (Hutchby 2005), news interviews (Heritage 1985), and meetings (Barnes 2007). While sequential and functional properties of formulations and the ways in which they are adapted to institutional settings have been explored in considerable depths, the semantic and turn-constructional aspects of formulations did not figure as prominently in prior research (Deppermann 2011, this volume). Still, practices of formulation differ in terms of the semantic work they do in interaction. They use specific linguistic designs of turn-construction for performing specific semantic operations, which have specific import for the ensuing interaction. This paper deals with one such practice of formulation which is characterized by a specific interactional semantic operation: the transformation of a description by a prior speaker into a categorization by the next speaker. Sequences of this kind are a "natural laboratory" for studying the differences between descriptions and categorizations as two of the major linguistic resources for constructing versions of actions, events and states of affairs. I will call such transformations of a descriptive version into a categorization 'notionalizations': An account full of indexical, temporal, personal etc. details is formulated as being an instance of an abstract category. Notionalizations can be both gist- or upshot-formulations (see Heritage and Watson 1979). ${ }^{1}$ Their specialty as a distinct practice of formulation lies in the transformation of one descriptive practice (description) into another one (categorization). The main body of this paper focuses on one specific practice of notionalization, i.e., the explication of an inference from a partner's prior turn using the German connective also in the initial position of a TCU. After the description of the turn-design and the semantic properties of also-notionalizations ("Turn-Design and Semantics of Also-Notionalizations"), their use as a situated professional resource ("Notionalizations as Professional Resources"), their potential for creating emergent keywords ("Notionalizations as Grounds for Emergent Keywords") and their complex relationship with respect to intersubjectivity and participant's strategic ends ("Strategic Design and Disputability of Notionalizations") will be analyzed. "Other Practices of Notionalization" section enlarges the picture, dealing with a very different practice of notionalization, i.e., identity-categorizations as an upshot of stories. Conclusion from comparative analysis will be drawn in "Conclusion" section, which discusses interactionally relevant aspects of variation between different practices of notionalization and reflects upon their commonalities.

\footnotetext{
${ }^{1}$ Although there are clear cases, the distinction between gist and upshot is very hard to draw in many cases, both semantically and pragmatically. This holds also for several of the cases discussed in this paper.
} 
This study rests on 30 instances of also-notionalizations from various transcribed audio- and video-corpora of talk-in-interaction with a total duration of $15 \mathrm{~h} 5 \mathrm{~min}$ (127 min doctor-patient-interaction, $178 \mathrm{~min}$ psychotherapy sessions, $165 \mathrm{~min}$ mediation sessions, 72 min meetings, 95 min conversations among adolescents, 270 min televised debates). In addition, some 30 instances of other kinds of notionalizations from these corpora were considered.

\section{Turn-Design and Semantics of Also-Notionalizations}

An example is \#1 from a behaviour therapy session. The patient had told the therapist that he will start a new job the next day. Earlier he had complained that he felt overwhelmed during his last job. The therapist now asks the patient about his feelings about the next day.

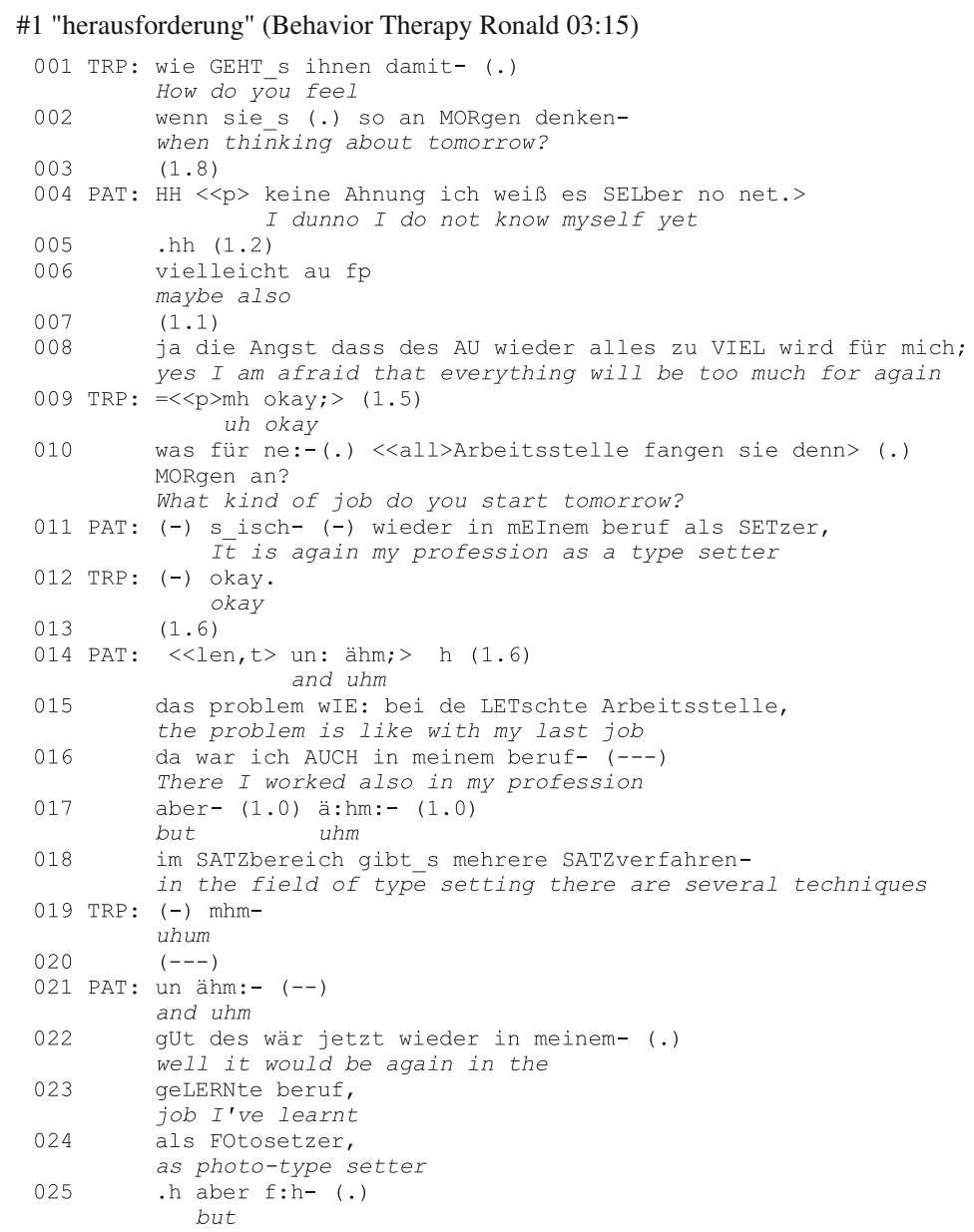




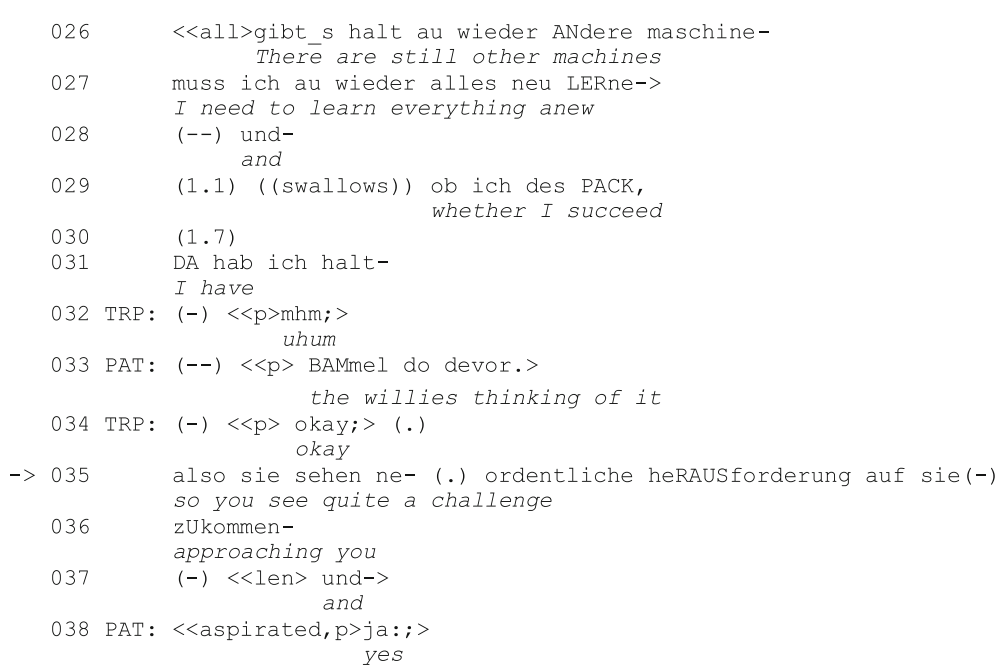

\section{The Descriptive Version}

The therapist asks the patient how he feels about the new job he will start tomorrow (lines 001-003). Hesitatingly (see pauses in lines 003, 005, 007), the patient prefaces his turn with epistemic disclaimers (line 004: "keine ahnung ich weiß es selber nicht") and hedges (line 006: "vielleicht"); using a very vague statement ("alles zu viel für mich"), he confesses that he is afraid he won't be able to cope with what is going to be expected of him (line 008). As the therapist asks for details of his new job, the patient compares it to his previous one (lines 015-016) and gives background information about the variety of machines used in his professional field (lines 018-026); he states that he has to learn to use new machines (line 027) and again concludes that he is afraid of not being able to comply with the exigencies of the new job (lines 029-033). The patient produces a multi-unit turn description in which he

- compares situations across time (lines 015-016)

- offers background information (line 018), which serves as an explanation for his fears (lines 026-027),

- underscores the stress emanating from his task by degree particles (au wieder, lines 008, 026-027), and

- indexes evidentiality of his argumentation by a modal particle (halt, line 031).

The patient produces a complex description which is designed to present argumentative evidence for his fears. It is recipient-designed in displaying his assumptions about the therapist's lack of knowledge concerning his professional requirements and his professional biography. 
The Notionalization

The therapist formulates the patient's account within one TCU as "also sie sehen eine ordentliche herausforderung auf sie zukommen" (so you see quite a challenge approaching you, lines 035-036). The turn-initial conclusive connective also displays that the nationalization is to formulate an inference about an implicit meaning which is, however, treated as being already communicated by the partner in a Gricean sense (Grice 1989).

The formulation refers back to the whole prior multi-unit turn of the patient. Compared to it, the formulation is short-it is only one sentence. In essence, it categorizes the upshot of the patient's turn as a 'challenge' by the noun "herausforderung," which carries the semantic weight. The verbal phrase "auf sich zukommen sehen" (you see approaching you) does not contribute much to the semantics of the turn, because it consists of serial verbs with a light semantics expressing future tense and movement. Besides the upgrading attribution "ordentliche" (considerable), the formulation is not modified by mitigation, self-repair, etc. The therapist's formulation focuses exclusively on the practical and emotional meaning of the new job for the patient. It does not take up all other temporal, professional, referential, comparative, and argumentative details which were present in the patient's account (see above). Although the categorization as a challenge takes up the patient's display of fear, it alters and reframes it in terms of something which has to be faced. As is typical of formulations in psychotherapy, this formulation is geared to a therapeutic end (cf. Antaki et al. 2005; Antaki 2008; Rae 2008), in this case, to encourage the patient to grapple with the new tasks waiting for him in the near future.

By transforming the patient's lengthy account into a succinct and clear-cut categorization, the therapist's formulation also reduces it to what can be seen as a neat answer to his initial question in lines 001-002: how do you feel when thinking about tomorrow? The formulation thus is not only a retrospective second-position activity concerning the patient's account, it is also a third position formulation of what is to count as the interactionally relevant content of the answer to the initial question (cf. Heritage 1985; Hutchby 2005). Therefore, while being officially designed as merely providing the gist of the patient's version as he himself intended it to be, the semantic transformation of the patient's version by notionalization bears some similarities to repair: It provides for the coherent interpretability of the patient's turn with respect to the therapist's line of questioning, assimilating it to his frame of reference as it were.

A second extract from the same interaction shows how notionalization can be designed even more economically. The patient talks about the situation of his partner (both of them are HIV-positive). 


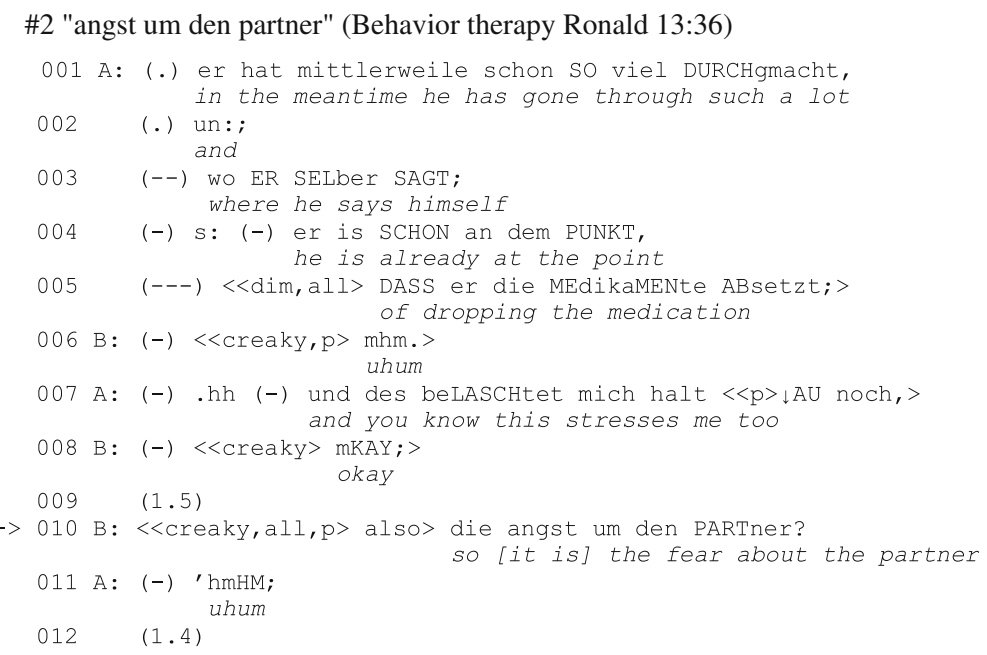

\section{The Descriptive Version}

The patient gave a lengthy description of the illnesses his partner has suffered from in the last months. He concludes it by stating that his partner intends to drop his medication (lines 001-005) and he describes his own emotional reaction to this as being stressed (line 007).

\section{The Notionalization}

After an acknowledgement token ("mkay," line 008), the therapist formulates an inference from the patients description: also die angst um den partner ("so [it is] the fear about the partner," line 010). Syntactically, the formulation is tied back to the first version by the connective also to index an inference from the prior turn. The elliptic syntactic construction [also $+\mathrm{NP}]$ without a finite verb is a common way to formulate a next turn meant to be an explication of an inference which is taken to express some meaning which the partner has implicitly communicated. Semantically, the formulation transforms the prior version in at least two important ways. First, it suggests a clear-cut qualitative categorization of the emotional state of the patient as "angst" (fear) and of its object (the partner), while in the patient's version, the emotion was adumbrated only vaguely in terms of emotional (di)stress ("belaschtet mich," stresses me, line 007) and he did not make clear what exactly was the object of the fear (the well-being of the patient's partner, the consequences of his partner abandoning his drugs for the patient himself, etc.?). Secondly, the formulation is restricted to a condensed and de-temporalized categorization. The patient's first version was a more detailed narrative and somewhat vague description, which related several events and actions to each other in terms of 
causes, consequences and intentional instrumentalities, thus contextualizing his own reaction in a larger course of events. The therapist's notionalization, however, is purified of all situational details and focuses exclusively on the patient's emotional state, thus lending the processes the patient referred to the reifying character of a discrete referent 'fear about the partner'. In this way, the patient's description of an interactional process is transformed into a categorization of his own psychological state.

The notionalizations studied in this paper are all prefaced by also. In German, also is the most common item to index a formulation which is framed as having been meant implicitly by the prior speaker in his/her previous turn. ${ }^{2}$ Also is not exclusively used for notionalizations, but it is a routine device for prefacing formulations in German, and it is by far the most common item to be used for indexing a notionalization. Its discursive function and its semantics as a preface to formulations are identical to English so in this position (see Antaki et al. 2005; Drew 2003; Heritage and Watson 1979; Hutchby 2005). ${ }^{3}$ Still, there is an important syntactic difference between German and English: In contrast to English so, also can be used in non-sentential formats as well, i.e., introducing a TCU with only phrasal syntax (e.g., also + noun, nominal phrase, prepositional phrase, or adjective), like in \#2, line 10 "also die angst um den partner". This syntactic opportunity allows to produce a "pure" notionalization, i.e., a TCU which includes no other semantic material (in terms of open class items) than the notionalization itself, thus highlighting it economically (see also \#4, 5, 9).

The practice of notionalization crucially involves formulating the partner's previous version as talk about an instance of an abstract category. The category is nearly always expressed by a noun phrase in my data. ${ }^{4}$ This 'is an instance of' -relationship of notionalizations is distinctive. It contrasts with other practices of formulation, which give a description or make a claim which expresses some causal, instrumental, temporal, etc. relationship. Notionalizations delete most details of the narrative and descriptive first versions they formulate, i.e., spatial, temporal and personal references, and they dispense with hedges and mitigation. Because of their abstract nature, notionalizations can subsume several events and states under the same category. Most importantly, notionalizations condense sequences of actions and events in just one encompassing, monothetic term, whereas in the prior account they were described polythetically according to a

\footnotetext{
2 There are still other linguistic resources to do this, which are less often used, like das heißt (this means) and $d u$ meinst (you mean). The explication of inferences which are treated to be communicated by the partner needs to be distinguished from formulations which are framed as being unilateral inferences from the recipient's point of view (with no implication made that the producer of the prior account has intended the meaning made explicit by the formulation) and from formulations which are framed as expressing a mere or even improbable inference (see "Other Practices of Notionalization").

3 Still, also can be used for various other functions as well, e.g., for indexing self-repair, projecting dispreferred activities, or opening up a lengthy narrative (Alm 2007; Konerding 2004). Note, however, that the specific semantics and discursive function of also depends on its position within sequences and turns. Also used as a marker of formulation is distinctive in terms of being produced turn-initially (rarely turn-medially) in the TCU which follows a description or narrative produced by another speaker.

${ }^{4}$ In my data there is only one case where an adjective is used for nominalization.
} 
temporal, conditional, causal or instrumental logic. ${ }^{5}$ Together with this monothetic design, they tend to reduce the fluent, negotiable and open character of narratives to a more fixed, clear-cut definition of things, which may also reduce some of the vagueness implied in the first version (but see below). Paradoxically, while notionalizations always express abstract concepts, they receive a distinct, thinglike status via their expression by nouns. ${ }^{6}$ The nominal conceptualization confers the abstract matter distinctness, referability as an individuated object and a kind of independent existence (cf. Kress and Hodge 1979: Ch.2), abstracted from events, actions, situations and actors, to which the abstract property would be tied in a descriptive account.

There are two further structural properties which are related to the categorical reduction of versions by notionalizations: de-temporalization and de-agentivization. First, temporal indices can be omitted. While it is constitutive of every notionalization that narrative temporal sequences are subsumed under a category, de-temporalization is enabled further by the possibility of producing the notionalization using only a (nominal) phrase, i.e., without a temporally marked verbal phrase as in \#2 "die angst um den partner". Second, most notionalizations in my data make use of grammatical constructions which do not encode agency. ${ }^{7}$ For example, the source of the "herausforderung" (challenge) in \#1 is not expressed. This would be necessary when using the verb herausfordern (to challenge), because it requires a subject phrase denoting an agent who or a source which causes the challenge. The agentless formulation avoids attributing responsibility (cf. Kress and Hodge 1979: Ch.2): Neither the patient nor his job conditions are blamed for the problems reported. In \#2, the notionalization "die angst um den partner" neither states who or what causes the fear, nor does it explicitly assign the patient a role with reference to the fear (e.g., experiencing it, being responsible for it, suffering from it). ${ }^{8}$ In sum, the transformations effectuated by the morphological and semantic properties of notionalizations consist in selectivity, abstraction, summarization, shortness and reification, with the additional potentials of timelessness, agent omission, and specification.

Notionalizations, thus, are made to purify versions from indexical details. Still, somewhat paradoxically, they stand in a situated and partly reflexive relationship to the prior versions they formulate (see also Bilmes this volume regarding specifications). In order to get, e.g., what the challenge ("herausforderung") the patient expects in \#1 consists of, how it is caused and why it is relevant, the notionalization needs to be understood with respect to precisely those details of the first version which are not explicitly covered by the notionalization.

\footnotetext{
5 The terms "monothetic" and "polythetic" are borrowed from Husserl (1982: §119; see also Schütz 1967: 75-78).

6 Langacker (2008) claims that the basic semantic property of nouns and NPs is to conceptualize their referent as a discrete entity.

7 See Duranti (2004) for a survey on the linguistics and pragmatics of agency.

${ }^{8}$ However, "des (belaschtet mich)" (this (stresses me), line 007) can be understood to be the antecedent of "die angst um den partner". So, "angst um den partner" would be a analeptical substitute to be completed by the verbal phrase from the patient's last TCU.
} 
The notionalization is not a self-contained semantic unit, but its interpretation rests on the first version it is retrospectively linked to. The first version thus provides for a partial local definition of the meaning of the notionalization, which, however, has the potential to be understood in a more general sense. This is because the first version does not provide for the full situated semantics of the formulation. Part of the semantics of the formulation remains discursively opaque and has to be derived from semantic, cultural and professional background knowledge. This applies specifically to the aspect of the formulation which transcends and specifies the first version. The additional interpretation often cannot be derived from the interaction so far. Still, relevant aspects of it may be revealed and negotiated by the participants in their subsequent interaction (see \#4).

\section{Notionalizations as Professional Resources}

A robust finding about formulations, which is confirmed by several studies, is that they are used by institutional agents to selectively focus on and retain those aspects of first versions of laypersons which are judged to be relevant for further talk according to the institutional agenda (Heritage and Watson 1979; Antaki et al. 2005; Hutchby 2005; Barnes 2007). Drew (2003) shows by comparison of formulations in four institutional settings how they are tailored to specific institutional tasks in terms of their linguistic design, the selection of contents which are formulated and the local functions in their sequential context. This applies a fortiori to alsonotionalizations. With one exception, also-notionalizations in my data were produced only by institutional agents. ${ }^{9}$ This section is intended to show that the structural properties of notionalizations analyzed in "Turn-Design and Semantics of Also-Notionalizations" section make them particularly apt to be used for and adapted to institutional purposes.

Notionalizations often involve the use of language for special purposes. When a professional uses a technical term to formulate a layperson's prior account, this is a most striking index for the transformation of the lay perspective according to the relevancies of professional knowledge and institutional ends (see Bowles and Seedhouse 2007). Abstraction and reification on the semantic plane and nominalization and composite nouns on the syntactic plane are hallmarks of language for special purposes (see Roelcke 2005) - properties which make it a major resource for notionalizations. This is especially true for German. German morphology allows for nominalizations from other word-classes such as verbs, adjectives etc. very easily by various mechanisms of derivation (like nominalization by -ung as in herausforderung in \#1, cf. Rathert and Alexaiou 2010) and for composing compound nouns by a larger range of productivity than most other languages (see below \#6-7)": erklärungsnöte; cf. Eichinger 2000). Because of the powerful morphological generative options of German, nominalizations and compound nouns are available or can be generated on the spot according to semitransparent semantic principles. This morphological productivity allows the

\footnotetext{
9 In data from informal conversations, no also-notionalizations occurred.
} 
speaker to adapt his/her turn quite flexibly to locally arising necessities of formulating a succinct upshot from prior talk. An example is \#3: A general practitioner formulates the patient's account, in which she compares her troubles to those of her husband, by the canonical medical compound noun allgemeinbefinden ("general condition," line 010):

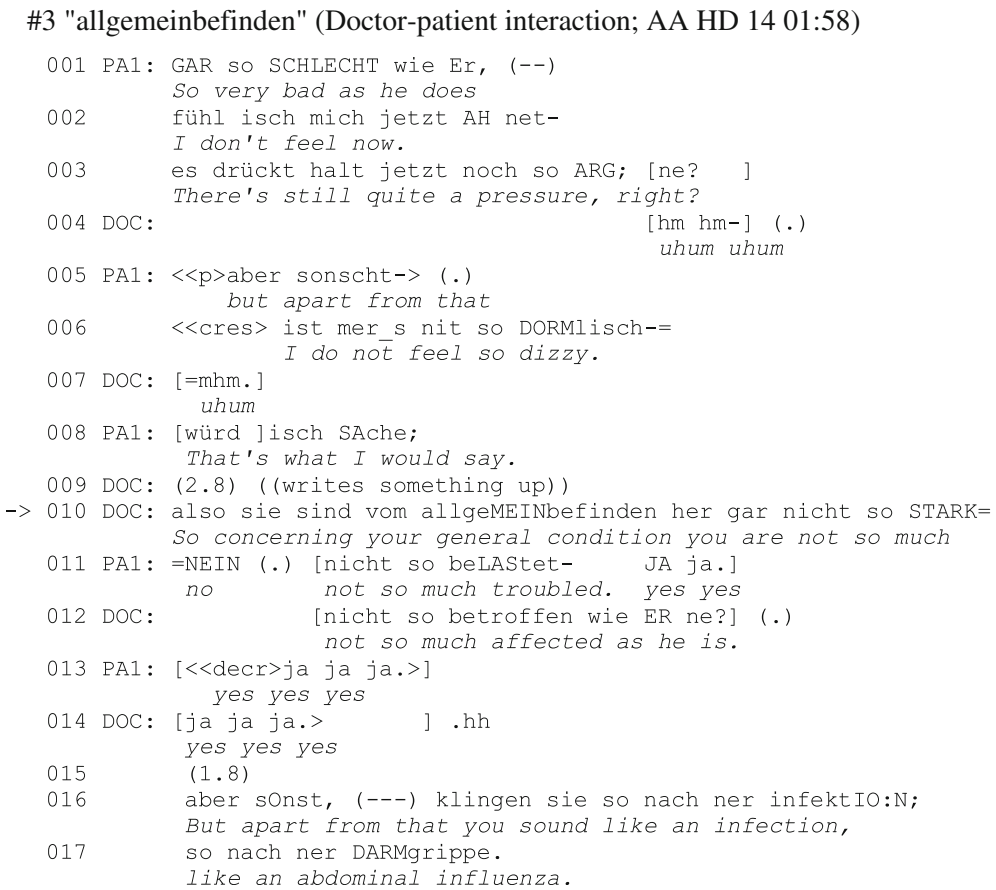

Again, the doctor's notionalization transforms a lengthy and rather vague, mundane description by the patient (PA1) (only partially represented in the extract), which is replete with formulaic phrases and self-repairs, into a clear-cut medical categorization. Its canonical status is also evidenced by the fact that the notionalization closes the topic (see the topic shift in line 016), the term allgemeinbefinden being used as the summarizing categorization of the prior stretch of topical talk. This is further corroborated by the fact that, precisely before taking the turn for the notionalization, the doctor takes a note, possibly using the same term in the patient's written record (line 009).

In "Turn-Design and Semantics of Also-Notionalizations" section, I noted that the semantics of notionalizations is partially discursively opaque, because it includes semantic properties which have to be gleaned from brought-along knowledge. As is well known, this may lead to misunderstandings, especially in the case of language for special purposes, because it might be unknown to the 
layperson or because words have a meaning different from their non-technical use. Sometimes, institutional agents show their sensitivity to this potential trouble-source by deploying at least part of the semantics of the notionalization in subsequent TCUs. In this way, its transformative semantic import with respect to the first version is made explicit at least partially in the interaction itself. A routine way to do this is to produce a list of items which are co-selected with the notionalization to delineate the scope of relevant inferences the professional has drawn from the layperson's account. \#4 is an example. The doctor asks the patient why he is afraid to fail in his new job:

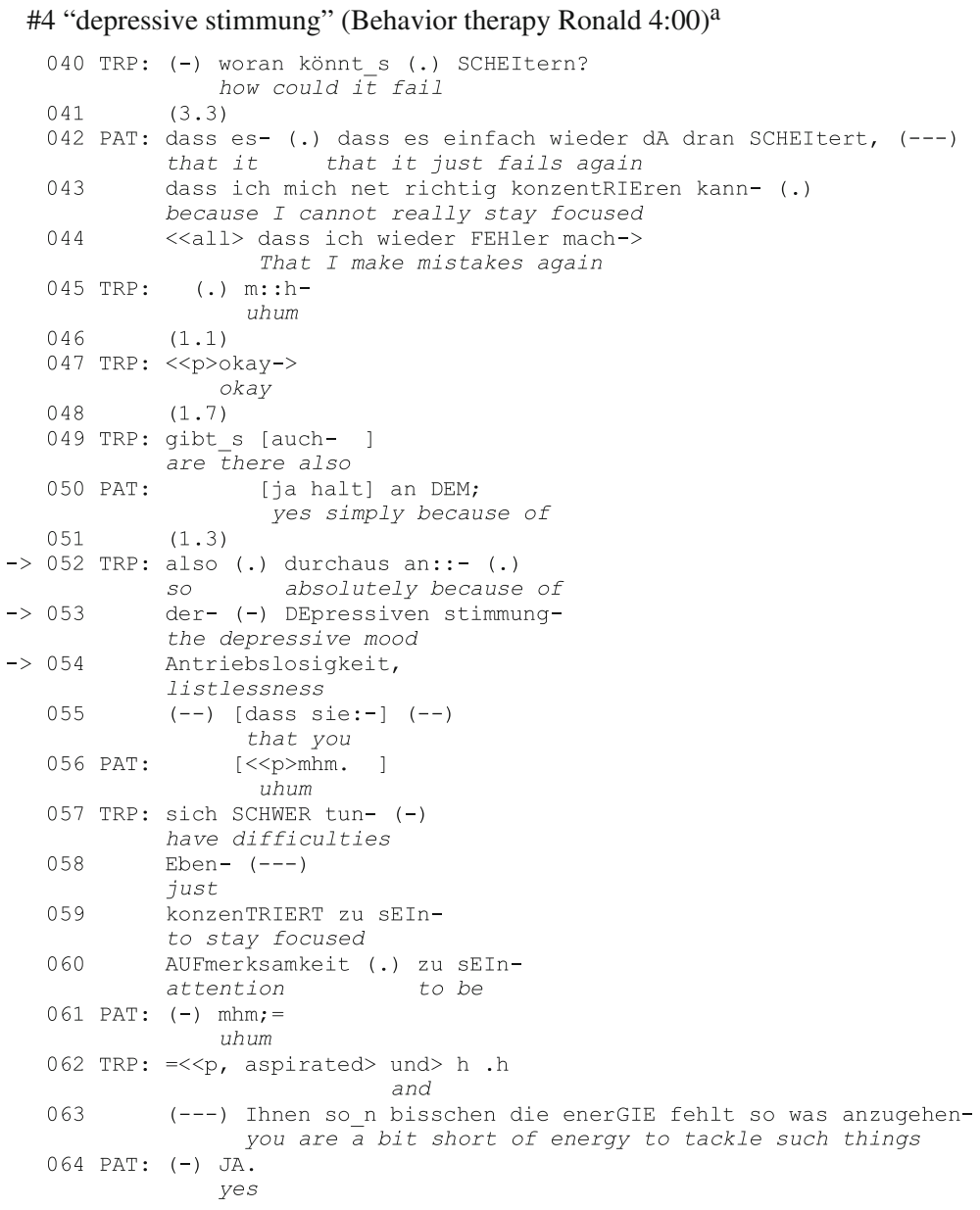

${ }^{a}$ This extract is the continuation of \#1. 
The therapist co-selects the categorizations "depressive(n) stimmung" (depressive mood, line 053) and "antriebslosigkeit" (listlessness, line 054) as notionalizations of reasons for what the patient reported, i.e., "sich schwer tun konzentriert zu sein aufmerksamkeit zu sein" (to have difficulties to stay focused, lines 043-044). The therapist's categorizations turn the patient's report into a report of symptoms. They subsume them under an overarching diagnosis (depression), making the patient's local account comprehensible in terms of a more general causative pattern (cf. Smith 1978). The semantics of the diagnostic categorization "depressive(n) stimmung" (depressive mood) is elucidated by the co-selection of "antriebslosigkeit" (listlessness), which connects the problems reported in the patient's prior turn back to his earlier reportings (not shown in the transcript), where he complained about lack of motivation. "antriebslosigkeit" (listlessness) cannot be derived directly from the patient's immediately prior account. Consequently, the therapist does not link it to the patient's turn in turn-initial position, but he produces it as a subsequent item to "depressive stimmung," thus constructing a list indexing their commonality as co-occurring items. This co-selection and the prolongation of the list in terms of difficulties with concentration and attention (lines 059-060) give an aperçu of both the wider professional semantics of the diagnostic categorization "depressive(n) stimmung" and of the way in which the therapist constructs coherence relations between various self-descriptions the patient has produced so far. The therapist's extended formulation thus makes explicit part of what he brings along to the notionalization "depressive stimmung," thereby clarifying its locally relevant semantics. At the same time, the professional notionalization itself enlarges the basis for further self-reflexive inferences, ${ }^{10}$ which are meant to be backconnected to the partner's first version, but which are mediated by the notionalization itself. The way the formulation is incrementally constructed, knotting together various aspects of the patient's accounts with respect to the psychological concept 'depression,' is a particular perspicuous instance of the workings of the documentary method of interpretation (cf. Garfinkel 1967) as used by the therapist. Still, the list of items is not presented as construction of coherence from the point of view of the professional outsider, but they are linked back to the patient's prior turn by the connective "also" ( $s o$ ) just as if they explicated an obvious inference already pre-understood and maybe even intended to be communicated by the patient.

A contrasting case from a televised discussion shows the "institutional fingerprint" (Drew 2003) of notionalizations in another setting. In this genre notionalizations are rather rare. Instead, moderators couch formulations in terms of succinct claims, which are attributed to the prior speaker as his/her position

\footnotetext{
${ }^{10}$ If we are to define this inferential property more precisely, we need to say that, according to the psychotherapist's theory, depression causes listlessness and problems of concentration as its symptoms. This causal relationship can be inferred from the fact that "depressive stimmung" is the first list item having the others as its sequel, but causality is not obviously indexed in what can be seen as being just a list of symptoms on a par.
} 
regarding the topic under discussion. Consequently, if a notionalization is used, this is done by providing a categorization which amounts to a claim. The following excerpt is from a televised debate on the German spelling reform. The moderator (MO) asks the linguistic expert (LI) about the changes which are about to come.

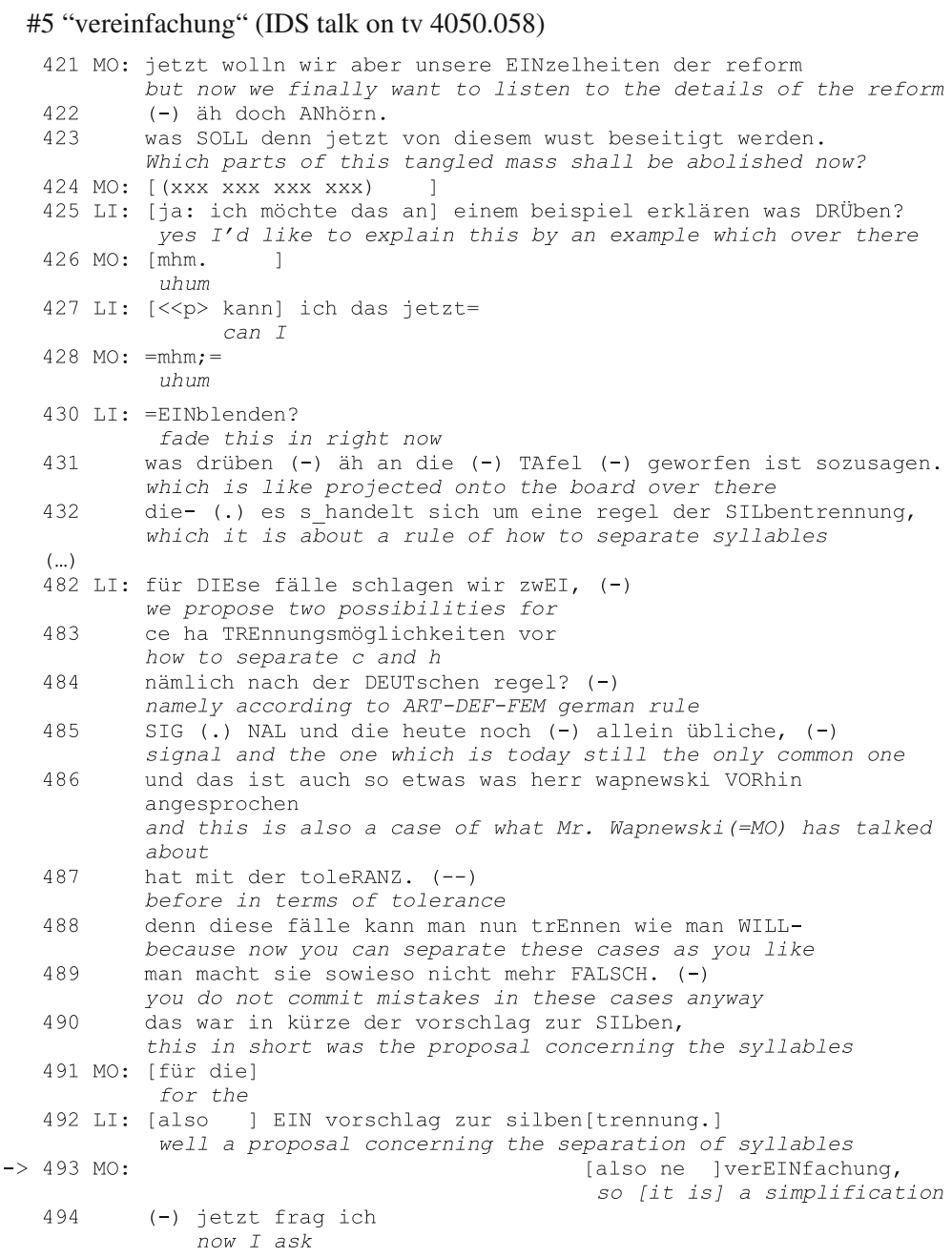

The linguist's (LI) lengthy account, which contains examples, alternatives and justifications, is succinctly formulated as the claim "also eine vereinfachung" (so [it is] a simplification, line 493). In contrast to other types of interaction and also to the linguist's prior turn, the notionalization does not use language for special purposes and the moderator does not project a confirmation slot for the linguist, 
but he immediately goes on to ask a next question. These two design features reflect the recipient-design of the moderator's formulation: It is addressed to an overhearing audience of laypersons, for whom the mediated interaction is interpreted in terms of clear-cut and easily comprehensible upshots with respect to the agenda of the moderator's question which purports to be asked on behalf of the audience (cf. Heritage 1985).

To sum up, in psychotherapy and in doctor-patient-interaction, notionalizations are used to formulate problems and diagnoses, and in order to focus on psychological states and processes of the patient (cf. \#1-4). In media talk, moderators use them quite rarely and, if so, in order to attribute a claim to the prior speaker. Notionalizations thus have rhetorical potentials which are most instrumental for accomplishing institutional agendas. They cannot be achieved to the same degree with other kinds of formulation, e.g., by providing another description. The structural and semantic properties of selectivity and abstractness, shortness and reification, which are distinctive for notionalizations, provide:

- the potential for focusing and clarification, i.e., to get to the point which is considered to be most relevant in a lengthy account and to single it out distinctively.

- the quality of reduction: the formulation omits all contingent detail, which can be taken for granted and which is considered as less important. AlsoNotionalizations allow for elliptical syntax and for omitting arguments which would need to be expressed if the notionalized concept was used as a verb. This may be especially convenient if encoding a responsible agent is not welcome.

- the reification of abstract concepts (cf. Fowler 1991: 80): nominal categorization strongly suggests the out-there-ness of abstract concepts invoked by the notionalization. It provides a very powerful means for the social construction of reality in terms of theoretical entities.

- re-usability: the nominal formulation in just one short phrase or even in only one word allows for coining canonical formulations. They can be reused as keywords on future occasions in order to co-refer back economically to complex matters talked about before. This will be shown in the next section.

\section{Notionalizations as Grounds for Emergent Keywords}

How notionalizations come to be reused will be shown in this section. \#6-7 are from another psychotherapy session. The patient, who is HIV-positive, told that he was anxious some time ago because of blood in his semen. He added that his doctor assured him that the blood was not related to a histological problem (i.e., not a symptom of AIDS). He says that he nevertheless still feels stressed about the issue. In the extract, the therapist pursues the question what the patient worries about. The patient answers by depicting a scenario in which a sexual partner notices the blood in the semen. 
\#6 “erklärungsnöte” (Behavior therapy Therapist white shirt 5:40)

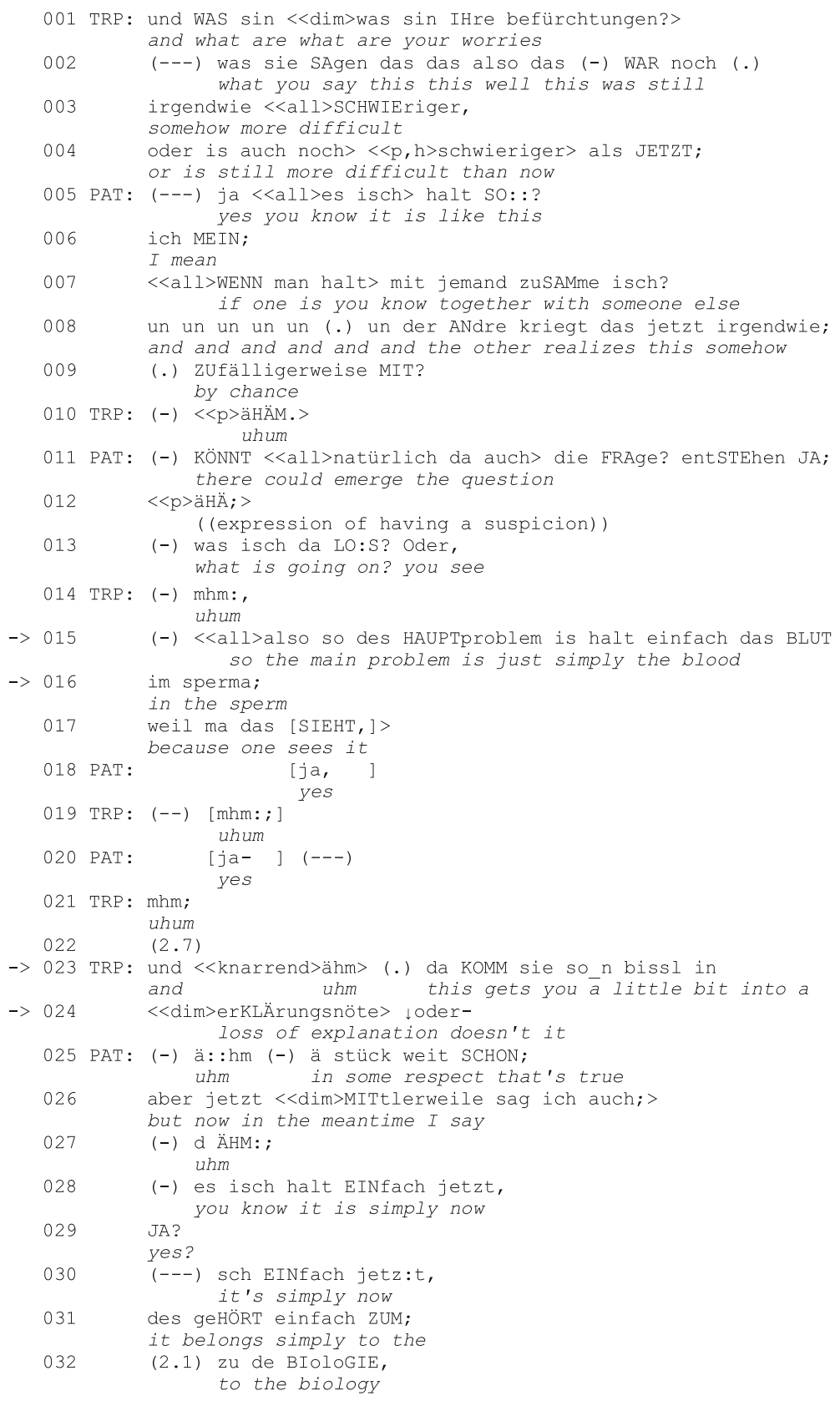

In order to account for his worries, the patient describes a hypothetical scenario: His sexual partner discovers blood in his semen, which might make the partner wonder about its cause (lines 005-013). The therapist concludes that the main problem of the patient lies in the visibility of the semen (lines 015-017), which 
leaves the patient at loss of explanation ("erklärungsnöte," line 017). The therapist's formulation transforms the patient's small story of the interpersonal scenario into a nominal categorization of a psychological problem. It provides the climax, which could be seen to be missing in the patient's account ${ }^{11}$ : How will he deal with the task of accounting for the blood in his semen to his sexual partner? Like in $\# 1$, the formulation in third position pinpoints a categorical problemdefinition as upshot of the answer to the therapist's initial question (lines 001-004).

The patient confirms the therapist's formulation only partially (line 025) and downgrades its relevance, saying that the blood can be explained as a normal biological phenomenon (lines 026-032). The therapist, however, stays with the issue and asks the patient again to account for his worries in the scenario he depicted. The patient replies with a formulation of his initial scenario:

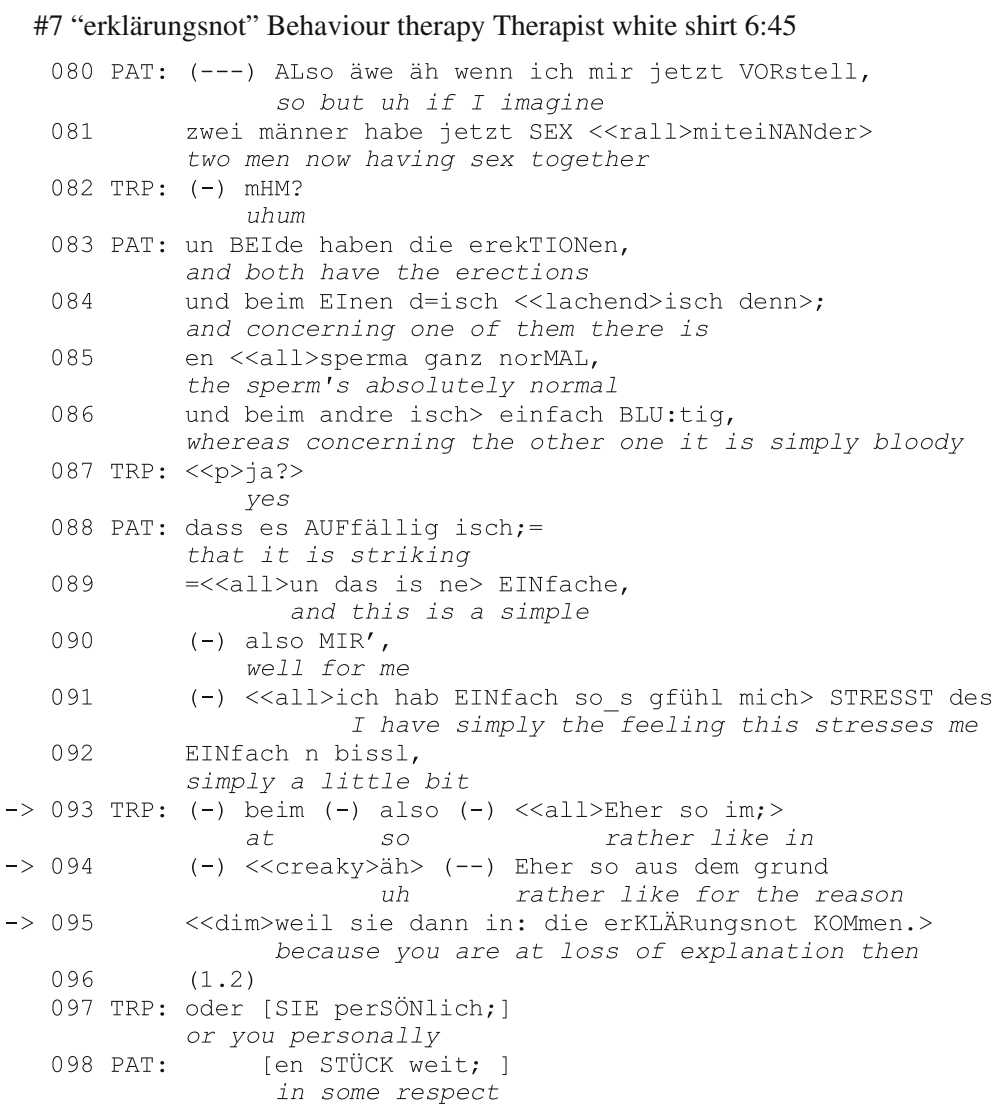

As the patient re-describes the scenario of the sexual encounter (lines 080-092), the therapist again responds with a categorical also-formulation. She re-uses the notionalization "erklärungsnot" (loss of explanation, line 095) from her prior first formulation of the patient's account in \#6, line 024. Interestingly, she now uses the

$\overline{11}$ See Bolden (2010) for similar cases of formulating unarticulated upshots of stories by and-formulations. 
definite article "die erklärungsnot" (loss of explanation), which co-refers to her first formulation as antecedent, thus displaying that the current formulation insists on the categorization introduced before. With the definite article, the referent of "erklärungsnot" is treated as a state which can be individuated for definite (co-)reference. Doing so, she also treats the patient's second version in \#7, lines 080-092, as a confirmation of her first formulation. By re-using "erklärungsnot," the therapist not simply produces it as a local explication of what the patient is taken to mean, but by its repetition, she displays that she has arrived at a stable explanatory hypothesis for the patient's worries. It is on the way to gain a canonical, term-like status. The notionalization lends the problem described by the patient the status of an instance of a general abstract category and treats it as an object with independent existence. ${ }^{12}$

In \#8, a categorization which has already been used in the context of an extended negotiation is then taken up as the notionalization of this negotiation. Subsequently, it becomes an emerging keyword for the results of the negotiation. The extract is from a meeting of adolescents and a youth worker, who are planning together a radio show together.

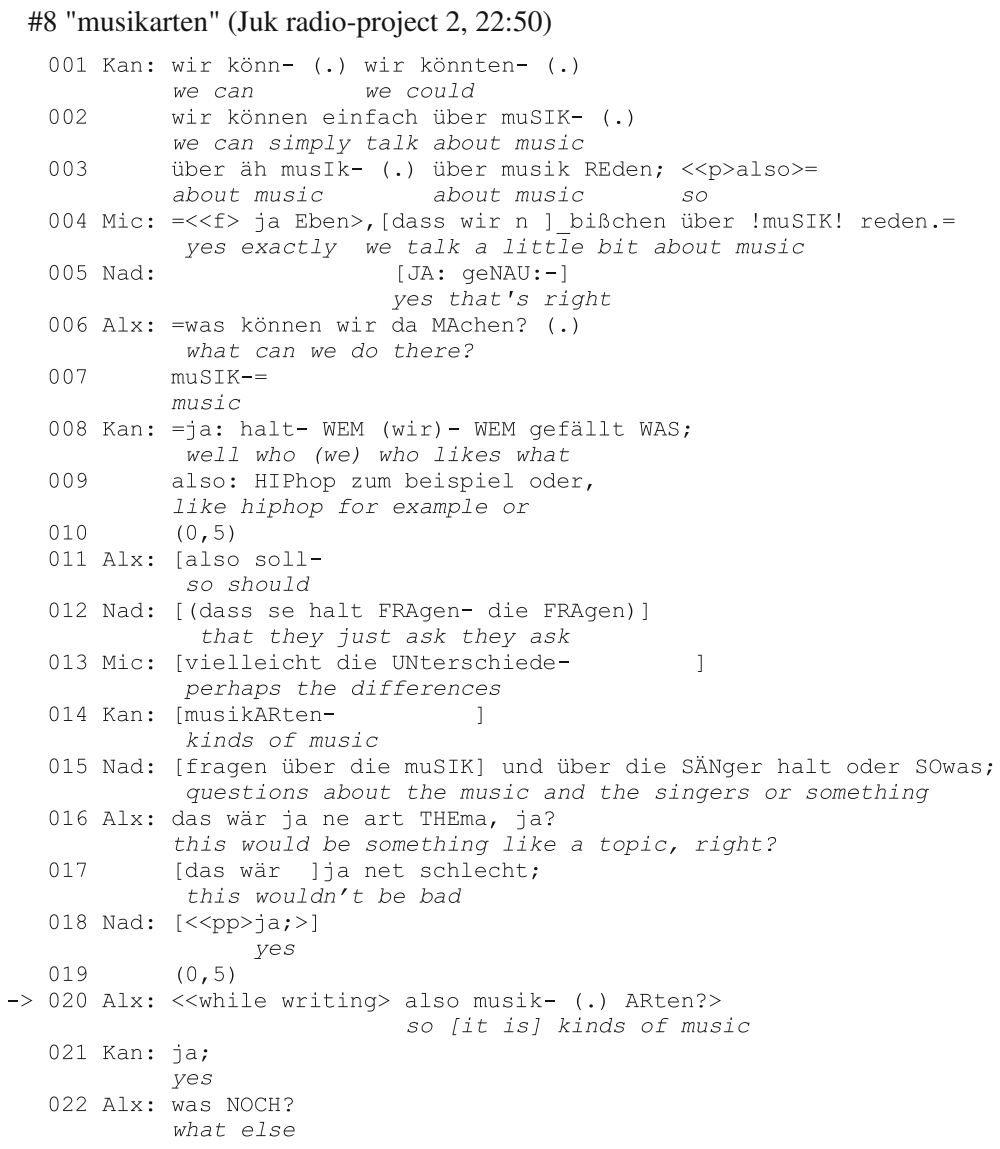

\footnotetext{
12 The therapist continues to use "erklärungsnöte" and morphological variants of it in the subsequent course of the therapy session as an explanation for the patient's problems.
} 
The adolescents propose various topics to be talked about in the show to be planned. They all revolve around musical matters. Kanen suggests to talk about kinds of music ("musikarten," line 014), a generalization of the example "hiphop" (line 009), which he produced earlier. The youth worker Alex selectively retains "musikarten" as the notionalization of the gist of the adolescent's negotiation and writes it up in the protocol of the meeting (lines 016-020). Little later (\#9), one of the girls, Michaela, re-focuses "musikarten" as the proper topic for talk when people will be phoning into address a song request.

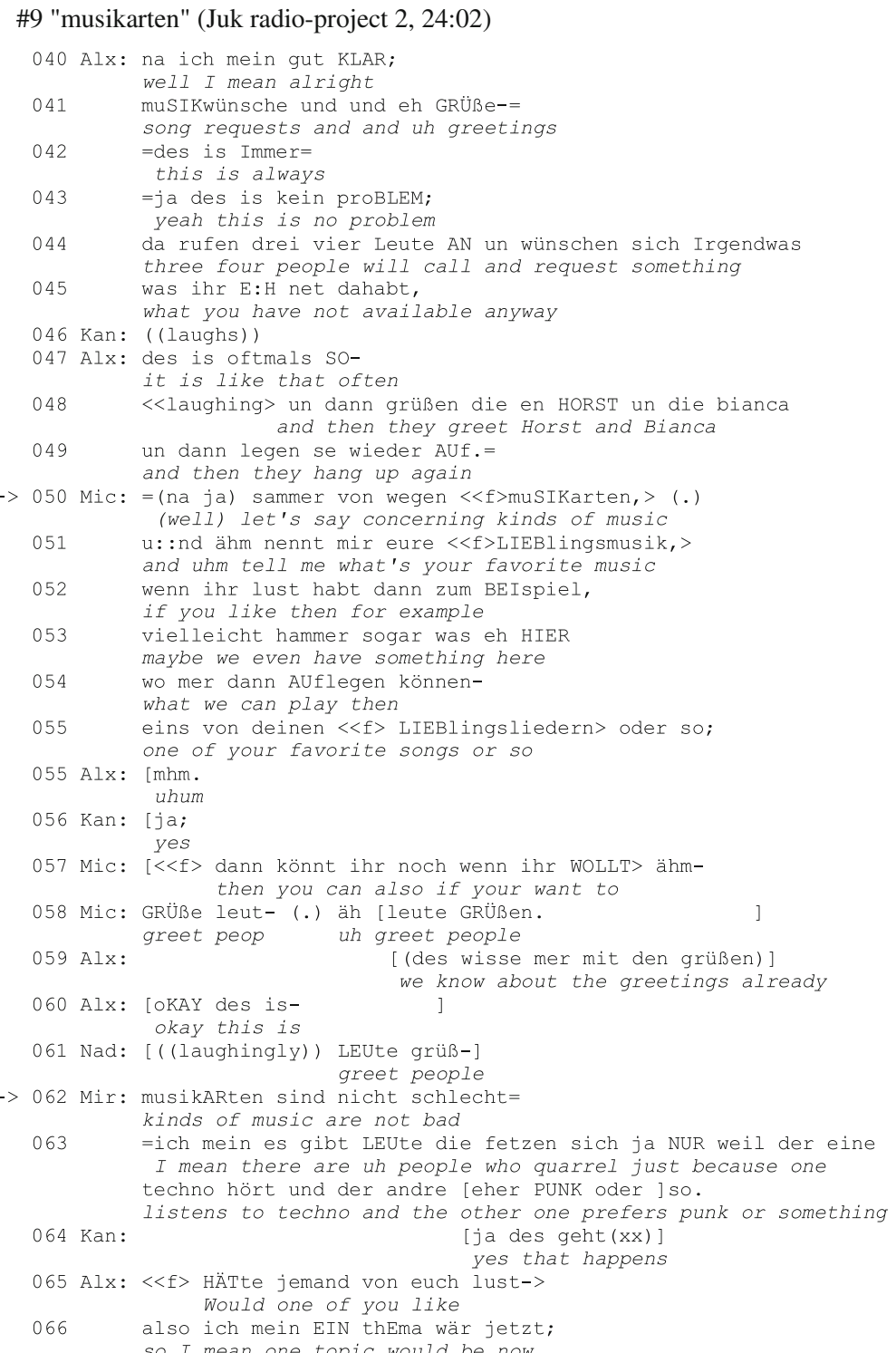


Michaela takes up "musikarten" (line 050) and suggests to use it as a starting point to talk with callers about what they like to hear (lines 051-058); Miriam chimes in and adds that "musikarten" are a suitable topic (line 062), because people often quarrel about which kind of music they like better (line 063). "Musikarten" thus becomes the emergent canonical term of reference for describing the kind of topic to be discussed in the broadcast. Thereby, its semantics is locally elaborated by adding new features of its potential for engendering talk.

We can see in \#6-9 how notionalizations, which were locally occasioned by a partner's turn, become emerging keywords for the subsequent interaction (see also Bilmes 2008 for an example). They are used to subsume larger interactional sequences of topical talk and to re-contextualize their gist and upshots economically at later occasions. Re-using the same lexical from (or morphological variants of it) thus is a means to provide coherence over extended stretches of interaction. By using just a word or a phrase (the notionalization), features and histories of the interactional past are made locally available even if they were not dealt with in immediately prior turns. ${ }^{13}$ The first notionalization, which is produced as a locally contingent formulation, is the basis for later condensed co-reference to the original formulated version far beyond this version.

\section{Strategic Design and Disputability of Notionalizations}

Notionalization is a sub-class of formulation practices which reduce details (similar to summaries and glosses), while casting a specific (new) perspective on the things talked about in the prior account. As is typical of formulations (see Antaki et al. 2005), notionalizations are often used for topical closure by providing a categorical conclusion which is to subsume and put an end to the seesaw of negotiations (\#8 being an example). In this way, categorizations are used as means of transforming descriptions according to (sometimes one-sided, strategic) practical relevancies and for reducing conceptual and controversial complexity in the service of interactional progression (Bilmes 1981; Deppermann and Spranz-Fogasy 1998). Still, on behalf of this very property, they can open up sites for arguments over descriptive adequacy and thus re-open the issue they were deemed to settle.

This can be seen in \#10, which is from a mediation session. PRO and OPP are the opponents, MED is the mediator. PRO refers to the insults of which she accuses OPP of.

\footnotetext{
13 In order to provide for long-distance co-reference, expressions (words, phrases, etc.) must be specific enough in order to co-refer distinctively. Abstract and compound nouns do this job perfectly well, because they are much more rarely used than the more concrete basic-level words, which are generally preferred (see Rosch 1978).
} 


\section{\#10 "streit"/"disput" (IDS mediation 3001-03, 10:08)}

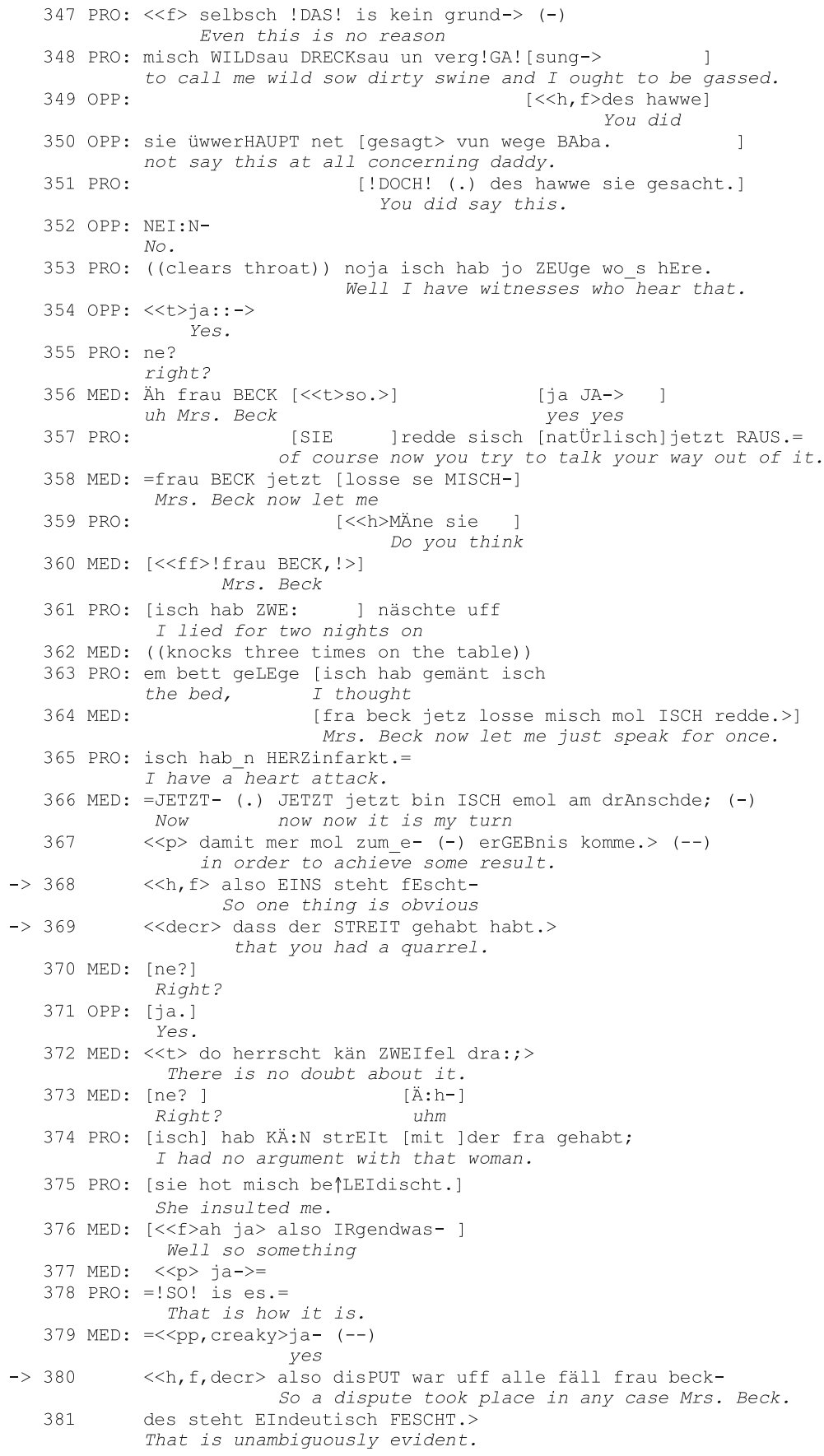


The mediator uses the notionalization "streit" (quarrel, line 369) to close the escalating argument between the opponents and to arrive at a minimal consensual definition of what happened-which is the prerequisite for reaching an agreement about legal and ritual claims for compensation. Interestingly, in this case the intersubjective validity of the notionalization is stated explicitly ("also eins steht fescht," so one thing is obvious, line 368). This rhetorical backing might be a hint that the mediator precisely does not assume that what is allegedly obvious is already accepted by the wranglers. This formulation, which ascribes agency to both PRO and OPP, is rejected by PRO, who replaces it with a formulation which attributes blame to OPP alone (line 373: she insulted me). The mediator insists on his position by using a synonym (line 380: "disput," dispute instead of "streit," quarrel), however, now producing an agentless statement ("a dispute took place"), which avoids to attribute blame to any of the wranglers. ${ }^{14}$

We can see here how the selection and acceptability of formulations hinges on the competing stakes participants have in the interaction. Their position to the issue at hand informs the formulations they advocate, while the formulations reflexively index their interactional positions. Insofar as formulations are consequential for outcomes of the talk, they are directly linked to both the institutional and the strategic business of participants in task-oriented settings such as the mediation session.

\section{Other Practices of Notionalization}

This section is to enlarge the picture both regarding the variety of practices of notionalization and the generality of its interactional uses and properties independent from the details of their functional design. The preceding sections have exclusively dealt with formulations which are designed to make explicit what the speaker treats as locally achieved common ground. In \#1-9, common ground is indexed by also-prefacing of the formulation, in \#10 an explicit declaration of common ground is added ("also steht fest," so one thing is obvious, line 368). Still, there are other practices of notionalization, which are not designed to express (alleged) common ground, but which explicate some unilateral generalization. This will be shown with respect to the notionalizations of stories: The story is interpreted in terms of giving evidence of an evaluative identity-ascription by assigning a nominal label of some social or personal identity-category to the story-protagonist (cf. Kallmeyer and Keim 1994). As we will see, this can either be done by the storyteller him/herself or by the story-recipient. We will start with a case of the latter. \#11 is from a rehearsal of a theatre performance at school. A theatre pedagogue tries to explain to the pupils how they should act in a scene of class reunion by reference to "practice" (i.e., social reality):

\footnotetext{
${ }^{14}$ Still, PRO does not accept this categorization either.
} 
\#11 "heuchler" (Juk-theatre project 6, 15:02)

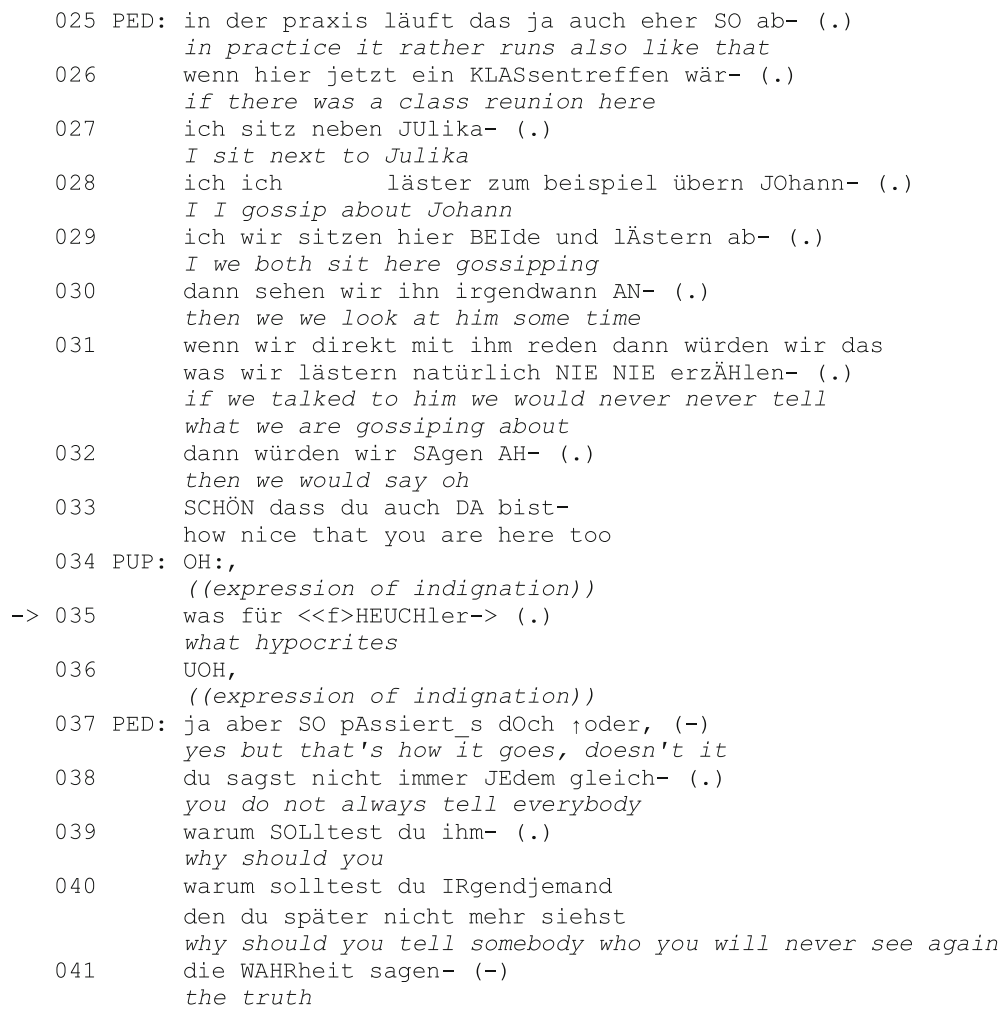

The pupil's notionalization ("was für heuchler," what hypocrites, line 035) aligns with the story structure, acknowledging its climax. But the pre-facing response-cry of indignation "OH:" (line 035) and the exclamation-format of the notionalization display that she does not affiliate with the morale which can be taken to be adumbrated by the story-teller and which he makes explicit ("that's how it goes," line 037) immediately after the pupil's negative response. The upshot of the story according to the pedagogue is the factualness of the social law not to tell people the truth about one's opinion of them while gossiping behind their backs. The pupil's notionalization "heuchler" (hypocrites), however, offers a competing interpretation of the story in terms of exposing a personal moral deficit of those people who act as the pedagogue describes. The recipient's notionalization thus seems to be perfectly in line with the story-teller in terms of capturing its descriptive content and its dramaturgical structure while sharply contrasting with it by assessing the storycharacters in terms of a negative identity-category as the upshot of the story.

Another unilateral use of a notionalization in terms of an evaluative identityascription can be seen in \#12, which is, however, different in terms of sequential placement and function. The extract is from a conversation among adolescents. Bernd tells a story about a woman who is said to strive for sexual relations with minors. Denis and Frank evaluate the story's protagonist as being chavvy and Denis 
starts to tell a second story about her as further evidence. At this moment, Bernd formulates the categorization "notgeile muddi" (desparate mummy) as the categorical upshot of the first story, which he had produced.

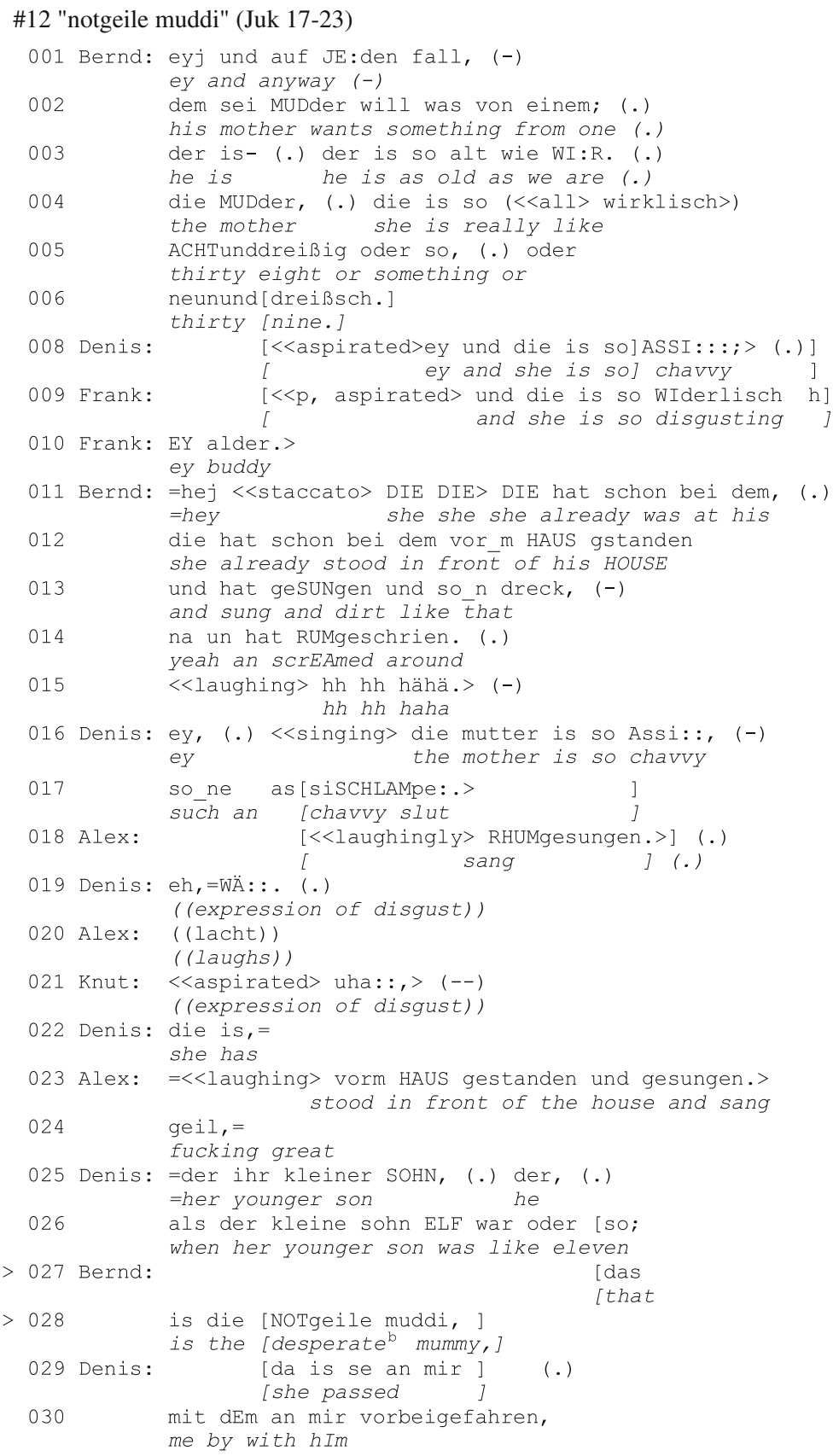

\footnotetext{
b "desperate" here means "desperately searching for a sexual partner".
} 
Like "heuchler" (hypocrites) in \#11, "notgeile muddy" (desperate mummy, line 028 ) is an evaluative notionalization of the personal identity of the storyprotagonist. This time, however, it is produced to make explicit and to reassert the point of the first story from the point of view of its teller (Bernd). This is different from what Denis, who is about to launch a second story, makes of the story-protagonist: With his comments to Bernd's story (see lines 008 and 016), Denis categorizes the protagonist as chavvy, Bernd's concern, however, is her sexual identity as desperate mummy, i.e., as a mature woman who publicly shows her sexual desires in indecent ways, directed to inadequate sexual partners who are still minors. The notionalization here is used to re-focus efficiently on the upshot of the story from the perspective of its original teller, precisely at a point in the interaction where a different interpretation threatens to prevail.

\section{Conclusion}

This paper set out to analyse one sub-practice of formulations, i.e., notionalizations. Notionalizations are formulations of descriptive or narrative accounts. The latter are multi-unit turn versions, which often contain vague and tentative references, which are unfinished and open to negotiation. They are episodic and located in space and time, offering a lot of contingent, situational, indexical detail. Notionalizations turn them into condensed, abstract, timeless, de-situated, and agentless categorizations, which are mostly expressed by a noun (phrase) within just one TCU. Notionalizations are ostensibly clear-cut, definite and purified of indexical details. They can be used to equip abstract concepts with a flavour of out-thereness, i.e., indisputable existence. They are used to construct social realities in a way which furthers the participants' practical ends, which may also be one-sided strategic. Their nominal or phrasal design makes them available as keywords for economical re-contextualization and co-reference on later occasions.

The main body of the paper has focused on notionalizations which are produced as purportedly intersubjective explications of what the prior speaker has already implicitly meant or what can be taken as agreed upon among participants. This type of notionalizations conforms most closely to the properties of formulations pointed out by Heritage and Watson (1979). In German, they are indexed by turn-initial also, which parallels English so, at least in functional, albeit not fully in grammatical respects. Just as has repeatedly been shown for formulations in English-speaking interaction, notionalizations as second-turn practices were only found in institutional interaction and they were always produced by the expert in expert-laypersonsinteractions. Indeed, notionalizations can be seen as one category-bound activity of institutional agents, both because of their property formulating the relevant gist or upshot of the partner's talk and because language for special purposes is often used for producing them. 
Looking beyond these findings, we can identify still other practices of notionalization. Another practice which is quite pervasive in interaction is the notionalization of stories: The notionalization interprets the story as a warrant to ascribe a social or personal identity-category to the story-protagonist, thus interpreting the story as an account of category-bound actions. As stories mostly have a moral upshot, these identity-categories have an evaluative imprint. An important difference to the also-type is that other notionalizations are rather unilateral, not purporting to draw some inference which is already part of the common ground of the participants. Their linguistic turn-design is different and they may be produced in different sequential positions, i.e., not immediately after the formulated version, but after some intervening talk (see \#12), or in a story preface, even before a narrative is delivered (not analysed here). Practices differ also in terms of the notionalization being used by the producer versus the recipient of the account to be formulated. So, notionalizations of stories differ from the also-type in terms of sequential positions, linguistic resources used and epistemic claims. Of course, they are not tied to institutional interaction, but they are used in informal conversation and by laypersons, too.

Further research is needed in order to explore the richness of the different practices of notionalization in more depth. The present study indicates some fields of research which promise to be particularly fruitful: Their construction both in terms of turn-design, their kind of linkage to formulated account and their morphological structure (nouns, compound nouns, noun phrases, but also adjectives, participles or verbs), their sequential organization ${ }^{15}$ and situated functions in specific interactional environments, and the ways in which they are used to manage intersubjectivity versus subjectivity in interaction.

Despite the differences between practices of notionalizations, there are some commonalities which seem to be characteristic of all kinds of notionalizations. They are devices to handle the complexity of descriptive topical sequences in interaction, which are inevitably ephemeral and which cannot be represented monothetically. Notionalizations tackle the problem of how to pin down and to transfer ephemeral interactional processes by using efficient interactional and linguistic means in order to retain what is relevant in the interactional history in terms of what can be represented within one category and one TCU for the interactional future. Abstraction and often also generalization are properties of notionalizations which allow for this. It makes them handy both in terms of cognitive operation (attention span, memory storage) and of interactional organization (efficient turn-construction within the availability of the floor, intersubjective alignment of interpretations, recontextualization of prior talk). Notionalization inevitably is a selective, perspectival, situated and self-reflexive mechanism. Still, its promise is to distill a realm of stable, enduring, factual representations from the fleeting vicissitudes of interaction, born in the see-saw of this interaction itself.

\footnotetext{
15 The abstract categorization may as well be put first and be expanded only afterwards (cf. Bilmes this volume).
} 


\section{Transcription Conventions GAT (Selting et al. 2009)}

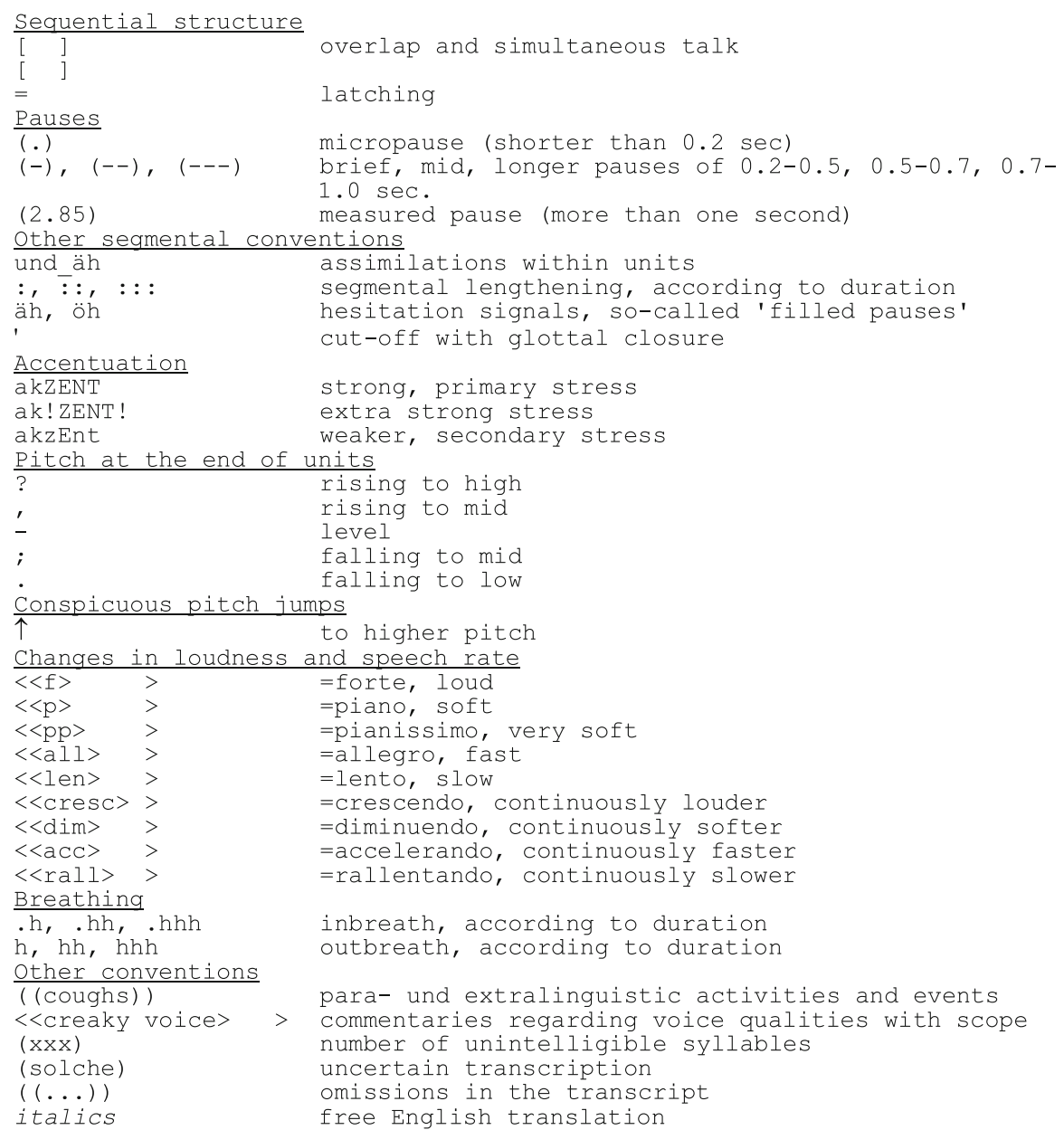

Acknowledgments I thank Jack Bilmes for comments on a prior version of this paper and Almut Helmes (University of Freiburg/Germany, Institute of Psychology, Dept. Rehabilitation Psychology and Psychotherapy) for the permission to use the data from the corpus "Behaviour therapy".

\section{References}

Alm, M. (2007). Also darüber lässt sich ja streiten! Die Analyse von also in der Diskussion zu Diskursund Modalpartikeln. - So you can argue about this! The analysis of also in the discussion of discourse and modal particles. Stockholm: Almqvist \& Wiksell.

Antaki, C. (2008). Formulations in psychotherapy. In A. Peräkylä, C. Antaki, S. Vehviläinen, \& I. Leudar (Eds.), Conversation analysis and psychotherapy (pp. 107-123). Cambridge: CUP.

Antaki, C., Barnes, R., \& Leudar, I. (2005). Diagnostic formulations in psychotherapy. Discourse Studies, 7(6), 627-647.

Barnes, R. K. (2007). Formulations and the facilitation of common agreement in meetings talk. Text and Talk, 27(3), 273-296. 
Bilmes, J. (1981). Proposition and confrontation in a legal discussion. Semiotica, 34(3/4), 251-275.

Bilmes, J. (2008). Generally speaking. Formulating an argument in the U.S. Federal Trade Commission. Text \& Talk, 28(2), 193-217.

Bilmes, J. (this volume). Occasioned semantics: A systematic approach to meaning in talk. Human Studies, 34(2).

Bolden, G. (2010). 'Articulation the unsaid' via and-prefaced formulations of others' talk. Discourse Studies, 12(1), 5-32.

Bowles, H., \& Seedhouse, P. (Eds.). (2007). Conversation analysis and language for specific purposes. Frankfurt am Main: Lang.

Deppermann, A. (2011, this volume). The study of formulations as a key to an interactional semantics. Human Studies. doi:10.1007/s10746-011-9187-8.

Deppermann, A., \& Spranz-Fogasy, T. (1998). Kommunikationsstörungen durch den Gesprächsprozeß. Zur Entstehung von Interaktionsdilemmata durch zeitliche Komplexierung-Troubles in communication by the process of interaction. How interactional dilemmata emerge by temporal complexities-. In R. Fiehler (Ed.), Verständigungsprobleme und gestörte KommunikationProblems and troubles in communication (pp. 44-62). Opladen: Westdeutscher.

Drew, P. (2003). Comparative analysis of talk-in-interaction in different institutional settings. In P. Glenn, C. LeBaron, \& J. Mandelbaum (Eds.), Studies in language and social interaction (pp. 293-308). Mahwah, NJ: Erlbaum.

Duranti, A. (2004). Agency in language. In A. Duranti (Ed.), A companion to linguistic anthropology (pp. 451-473). Oxford: Blackwell.

Eichinger, L. (2000). Deutsche Wortbildung -German word-formation-. Tübingen: Narr.

Fowler, R. (1991). Language in the news. London: Routledge.

Garfinkel, H. (1967). Studies in ethnomethodology. Englewood Cliffs, NJ: Prentice-Hall.

Garfinkel, H., \& Sacks, H. (1970). On formal structures of practical action. In J. C. McKinney \& E. A. Tiryakian (Eds.), Theoretical sociology (pp. 338-366). New York: Appleton-Century-Crofts.

Grice, H. P. (1989). Studies in the way of words. Cambridge, MA: Harvard UP.

Heritage, J. (1985). Analyzing news interviews. In T. A. van Dijk (Ed.), Handbook of discourse analysis (Vol. 3, pp. 95-117). London: Academic.

Heritage, J., \& Watson, D. R. (1979). Formulations as conversational objects. In G. Psathas (Ed.), Everyday language (pp. 123-162). New York: Irvington.

Husserl, E. (1982[1913]). Ideas pertaining to a pure phenomenology and to a phenomenological philosophy. First book: General introduction to a pure phenomenology. The Hague: Nijhoff.

Hutchby, I. (2005). "Active listening": Formulations and the elicitation of feelings talk in child counselling. Research on Language and Social Interaction, 38(3), 303-329.

Kallmeyer, W., \& Keim, I. (1994). Bezeichnungen, Typisierung und soziale Kategorien-Nominations, typification, and social categories-. In W. Kallmeyer (Ed.), Exemplarische Analysen des Sprachverhaltens in Mannheim-Exemplary analyses of the linguistic behaviour in Mannheim(pp. 318-386). Berlin: de Gruyter.

Konerding, K.-P. (2004). Semantische Variation, Diskurspragmatik, historische Entwicklung und Grammatikalisierung. Das Phänomenspektrum der Partikel also. - Semantic variation, discourse pragmatics, historical development, and grammaticalization. The phenomenal spectrum of the particle also. - In I. Pohl \& K.-P. Konerding (Eds.), Stabilität und Flexibilität in der Semantik (pp. 199-240). — Stability and flexibility in semantics-. Frankfurt/Main: Lang.

Kress, G., \& Hodge, R. (1979). Language as ideology. London: Routledge and Kegan Paul.

Langacker, R. (2008). Cognitive grammar. Cambridge: CUP.

Rae, J. (2008). Lexical substitution as a therapeutic resource. In A. Peräkylä, C. Antaki, S. Vehviläinen, \& I. Leudar (Eds.), Conversation analysis and psychotherapy (pp. 62-79). Cambridge: CUP.

Rathert, M., \& Alexaiou, A. (Eds.). (2010). The semantics of nominalization. Berlin: de Gruyter Mouton. Roelcke, T. (2005). Fachsprachen -Languages for special purposes. Berlin: Schmidt.

Rosch, E. H. (1978). Principles of categorization. In E. Rosch \& B. Lloyd (Eds.), Cognition and categorization (pp. 27-48). Hillsdale, NJ: Erlbaum.

Schütz, A. (1967[1932]). The phenomenology of the social world. Evanston, IL: Northwestern UP.

Selting, M., Auer, P., Barth-Weingarten, D., Bergmann, J., Bergmann, P., Birkner, K., et al. (2009). Gesprächsanalytisches Transkriptionssystem 2 (GAT 2). Gesprächsforschung, 10, 353-402. http://www.gespraechsforschung-ozs.de/heft2009/heft2009.htm, last accessed 13 June 2011.

Smith, D. (1978). K is mentally ill: The anatomy of a factual account. Sociology, 12, 23-53. 